\title{
Splitting tests: an alternative to determine the dynamic tensile strength of ceramic materials
}

\author{
J. Rodríguez, C. Navarro* and V. Sánchez-Gálvez \\ Department of Materials Science, Polytechnic University of Madrid, E.T.SI. de Caminos, Canales y \\ Puertos, Ciudad Universitaria s/n, 28040 Madrid, Spain \\ * Department of Engineering, Carlos III University, Avda. de Butarque 15, Leganés, 28911 Madrid, Spain
}

\begin{abstract}
Résumé. On étudie les possibilités d'utilisation de l'essai de traction indirecte (essai brésilien) en conditions dynamiques pour obtenir les proprietés mécaniques à traction des materiaux céramiques à hautes vitesses de contrainte. L'étude se fonde sur la réalisation d'essais mécaniques sur éprouvettes cylindriques placées dans la barre Hopkinson et observation par caméra photographique de haute vitesse de la nucleation et propagation de la fissure ainsi que sur des simulations numériques de l'essai par moyen de la méthode des éléments finis. On constate que les materiaux céramiques ont un comportement élastique jusqu' à la rupture et que la condition d'équilibre est atteinte avant la rupture de l'éprouvette, donc la méthode proposée peut être alternative pour determiner les proprietés dynamiques à traction des materiaux fragiles.
\end{abstract}

\begin{abstract}
In this work, the possibilities of splitting tests (Brazilian tests) to determine the mechanical properties of ceramic materials at high strain rates are analyzed. The study is based on the mechanical characterization of cylindrical specimens in the Hopkinson bar and the use of a high speed camera to observe the failure pattern. Additionally, a numerical simulation of the tests has been carried out using the finite element method. Results show that Brazilian tests can be an alternative to determine the dynamic properties of brittle materials when the elastic behaviour and the equilibrium state are ensured, and the failure is produced in the expected way.
\end{abstract}

\section{INTRODUCTION.}

Ceramic materials constitute nowadays a new area of research. Their highly attractive properties, such as hardness, corrosion resistance and good behaviour at high temperatures, are of great interest in different industrial applications. Thus, it is essential to determine their mechanical properties to use them in manufacturing components or structures. The mechanical characterization of ceramics is a task of great complexity, even at quasi-static loading rates, because the brittleness and hardness of these materials complicate the machining of specimens and the design of load transfer mechanisms. These difficulties are increased in the high loading rate regime, making almost impossible to employ techniques suitable for more conventional materials.

To this end, this paper proposes the extension of splitting tests to determine the dynamic tensile strength of ceramic materials. This type of test was originally developed by F. Carneiro [1] to determine the quasi-static tensile strength of concrete. Now, there is an ASTM standard (ASTM C 496-71) [2] to carry out this type of tests. As it is well known, a cylindrical specimen is loaded in compression with its axis perpendicular to the load direction. If the material behaves elastically, the tensile stress in the specimen is maximum and constant along the diameter coincident with the load direction and, consequently, failure must occur there. However, this standard cannot be applied for ceramic materials under dynamic conditions, because the extension of these tests to the high loading rates makes necessary to consider the wave propagation effects. A complete assessment of the splitting tests as a good method 
of determining the dynamic tensile strength should consider at least three critical aspects: the elastic behaviour assumption, the time evolution of the stress distribution in the specimen and the failure pattern. To analyze these factors an experimental programme has been carried out, with loaddisplacements records and high speed images of the tests. Additionally, a numerical simulation has been performed using the finite element code ABAQUS [3].

\section{EXPERIMENTAL TECHNIQUE.}

The dynamic splitting tests (Brazilian tests) have been carried out in a compression version of the Hopkinson bar, while for the quasi-static tests a conventional testing machine was used. A diagram of the dynamic test is shown in figure 1 .

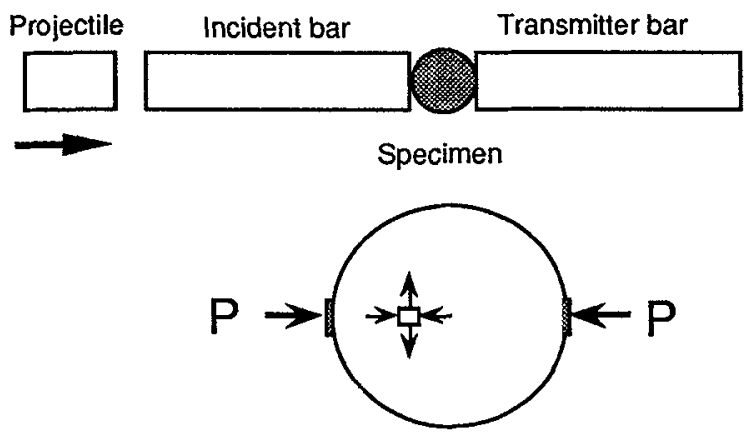

Figure 1. Dynamic Brazilian test diagram.

When a force, $\mathbf{P}$, is applied on a cylinder as indicated in figure 1, a material element along the diameter coincident with the application of the load is subjected to a compression stress, $\sigma_{\mathfrak{c}}$, and to a tensile stress, $\sigma_{\mathrm{t}}$ (uniform along the diameter) which values are:

$$
\sigma_{c}=\frac{2 P}{\pi L D} \frac{D^{2}}{r(D-r)} \quad \sigma_{t}=\frac{2 P}{\pi L D}
$$

where $\mathrm{L}$ and $\mathrm{D}$ are respectively, the height and diameter of the cylinder and $\mathrm{r}$ the distance from the element to the point where the load is applied [4]. As it is expressed in the last equation, it is possible to determine the material tensile strength in terms of the maximum force recorded, $P_{\max }$, and the specimen geometry. Although, it should be taken in mind that the specimen is under a biaxial stress state, with a compression stress higher than the tensile one. This fact invalidates a direct comparison between the results obtained in these tests with those of the simple tensile tests, unless the failure criterion be known.

In the quasi-static tests, the maximum force was provided by the load cell machine whereas, in the dynamic tests the maximum force applied to the specimen was derived through the traditional wave propagation method employed in the Hopkinson bar tests [5].

In addition to the usual records, a high speed camera (Imacon 700 Hadland Photonics) has been synchronized with the experimental device to capture high speed images of the specimen during the loading process and, specially, at failure. The electronic signals generated in the strain gauges sticked on the bars are used as a trigger to control the camera, the lighting and the starting time to capture images. Details about high speed photography techniques can be consulted in reference [6] 


\section{EXPERIMENTAL RESULTS.}

Two materials have been tested in the experimental programme: silicon carbide-silicon nitride compound (a refractory employed in furnace manufacture) of $2700 \mathrm{~kg} / \mathrm{m}^{3}$ and alumina $96 \%$ of purity and $3700 \mathrm{~kg} / \mathrm{m}^{3}$ (typical armour component). At least five cylindrical specimens was tested in each condition with the following dimensions: $10 \mathrm{~mm}$ height and $20 \mathrm{~mm}$ in diameter for the silicon carbidesilicon nitride compound, and $4.5 \mathrm{~mm}$ height and $18 \mathrm{~mm}$ in diameter for the alumina. In the Hopkinson bar tests the projectile was accelerated at $13 \mathrm{~m} / \mathrm{s}$, providing a loading rate of approximately $10^{6} \mathrm{MPa} / \mathrm{s}$, around seven orders of magnitude higher than in the quasi-static tests $(0.1 \mathrm{MPa} / \mathrm{s})$.

An example of the results obtained are included in the following figures. The force-displacement and the stress-time curves are shown in figures 2 and 3, respectively. As it can be seen the linear elastic behaviour of the material is confirmed by the first part of the force-displacement curve. On the other hand, figure 3 shows a stress versus time record, where the maximum stress value, corresponding to the material tensile strength, is also indicated. The complete results are summarized in table 1, where the dynamic tensile strength is compared with the quasi-static value for both materials.

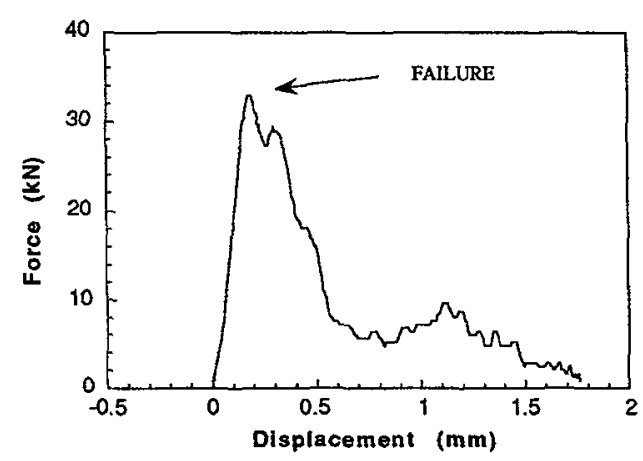

Figure 2. Force-displacement record

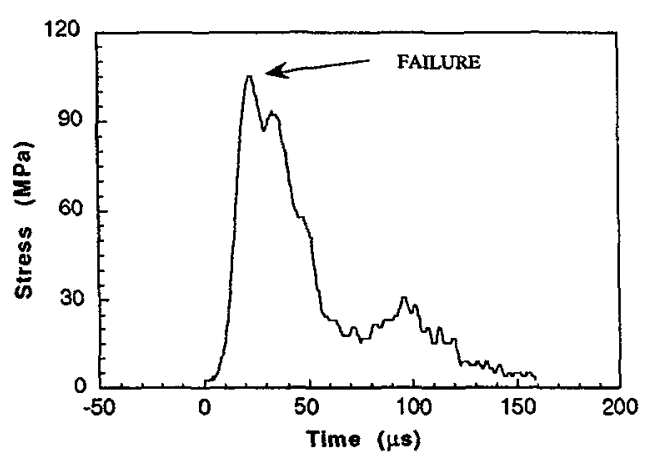

Figure 3. Stress-time record

Table 1. Summary of tensile strength results

Material

\begin{tabular}{|c|c|c|}
\hline SiC+NSi compound & $70 \pm 20$ & Static (0.1) \\
\cline { 2 - 3 } & $90 \pm 20$ & Dynamic (106) \\
\cline { 2 - 3 } Alumina & $250 \pm 40$ & Static (0.1) \\
\cline { 2 - 3 } & $190 \pm 40$ & Dynamic (106) \\
\hline
\end{tabular}

Finally, in figures 4 and 5, the images captured with the high speed camera in the tests of silicon carbide-silicon nitride compound are shown. In both figures the images are taken every $10 \mu \mathrm{s}$. Figure 4 corresponds to an apparently valid test which provided a value of $105 \mathrm{MPa}$ for the tensile strength, whereas in the second case (figure 5) the failure was localized simultaneously along three lines of the specimen, making inadequate the initial assumption about the ideal failure pattern and consequently, providing an invalid value for the tensile strength (84.7 MPa). 


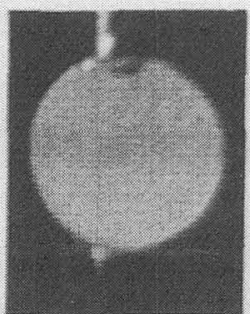

$25 \mu \mathrm{S}$

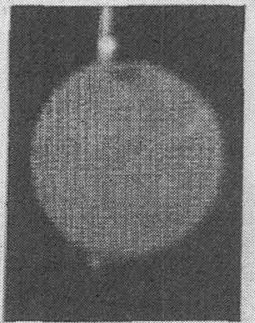

$15 \mu \mathrm{S}$

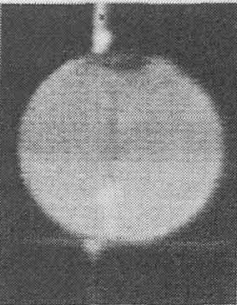

$45 \mu \mathrm{s}$

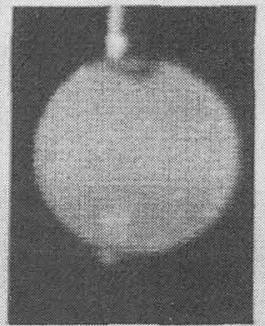

$35 \mu s$

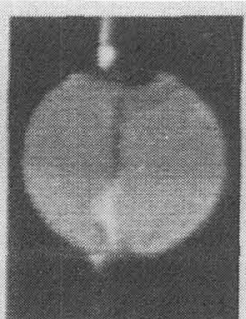

$65 \mu$

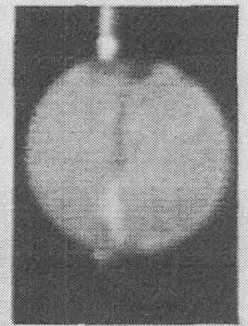

$55 \mu \mathrm{S}$

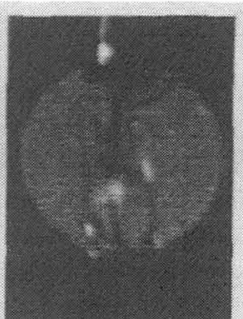

$85 \mu 5$

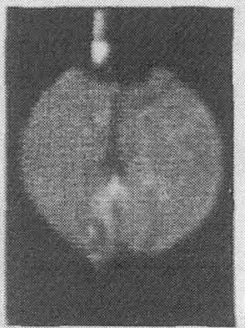

$75 \mu 5$

Figure 4, High speed images of a silicon carbide-silicon nitride specimen (Valid test)

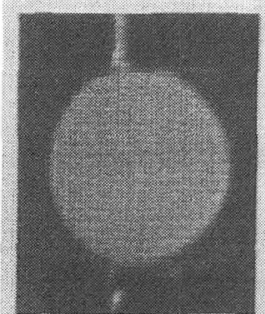

$25 \mu \mathrm{s}$

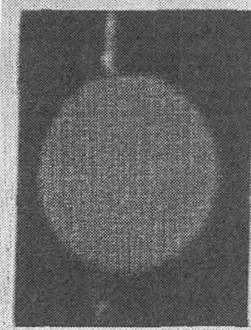

$15 \mu s$

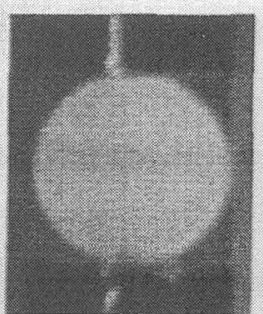

$45 \mu \mathrm{s}$

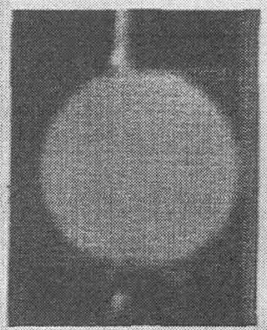

$35 \mu s$

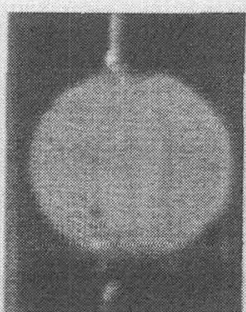

$65 \mu \mathrm{s}$

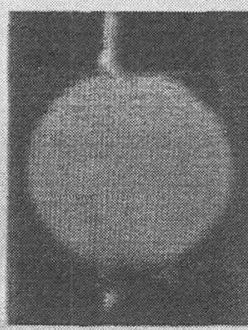

$55 \mu s$

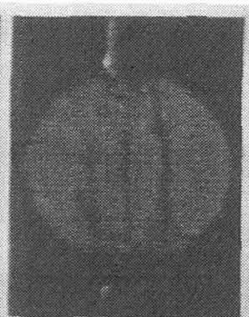

$85 \mu s$

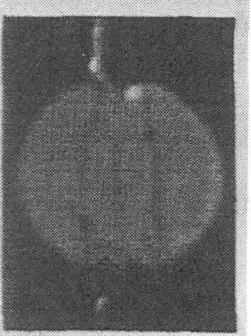

$75 \mu \mathrm{s}$

Figure 5. High speed images of a silicon carbide-silicon nitride specimen (Invalid test) 


\section{NUMERICAL SIMULATION.}

The numerical modelling process has been limited to the analysis of the silicon carbide-silicon nitride compound. To this end, the finite element code ABAQUS [3] has been employed. The cylindrical symmetry of the problem allowed to model half of the specimen through 1261 nodes and 400 rectangular elements with 8 nodes each (quadratic interpolation). The material behaviour had been assumed fully elastic with Young's modulus of $200 \mathrm{GPa}$, Poisson's ratio of 0.33 and density of 2690 $\mathrm{kg} / \mathrm{m}^{3}$. The load condition was applied to an end of the specimen by means of a trapezoidal velocity curve with a maximum value of $13 \mathrm{~m} / \mathrm{s}$ and a rise time of $20 \mu \mathrm{s}$. These data was obtained from the Hopkinson bar tests carried out in the experimental programme. To verify the modelling process validity, experimental and numerical values of the force transmitted through the specimen have been compared, providing a reasonable agreement. This fact, together with the experimental forcedisplacement records (figure 2) confirmed the appropriateness of the assumed linear elastic of the ceramic behaviour.

The objective of the simulation process was to determine whether the specimen fails before or after reaching the quasi-static equilibrium. This factor is critical because the expression used to calculate the tensile strength is only valid when the stress distribution in the specimen is similar to that of the quasi-static tests. The dynamic stress contours obtained in the simulation are shown in figure 6 at different times after the application of the load in one end of the specimen. In the first instants, the stress wave has not reached the other end, which is unloaded and, thus, it is meaningless to talk about force applied to the specimen. A little bit later, the stress wave reverberations have produced a more uniform stress distribution, although for our specimens $8 \mu \mathrm{s}$ is the minimum time to complete the process and to guarantee the symmetrical distribution and the equilibrium state. After that time, the material stress along the diameter coincident with the load direction is very well represented by the equation used in the static Brazilian tests, making possible to determine the stress at failure, that is, the dynamic tensile strength.

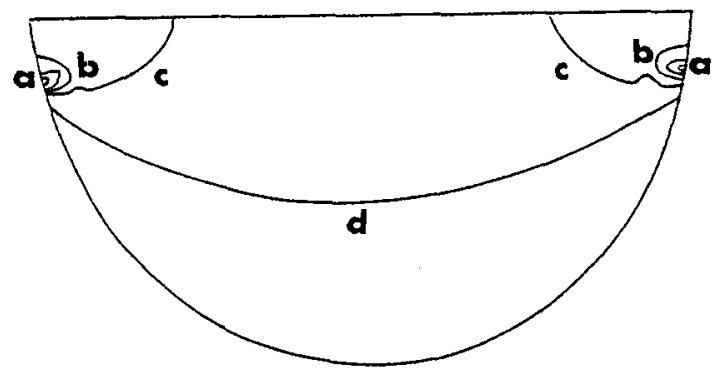

QUASI-STATIC

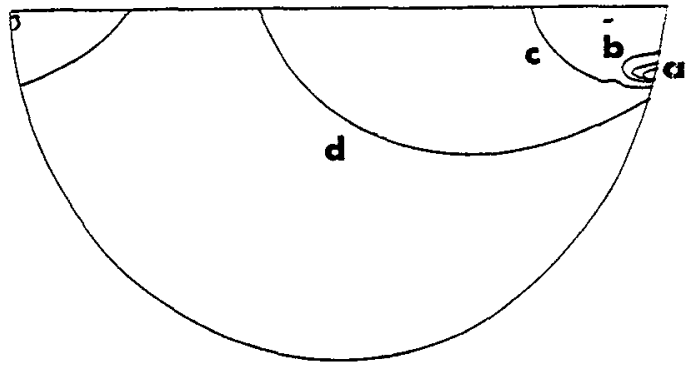

DYNAMIC ( $4 \mu s)$

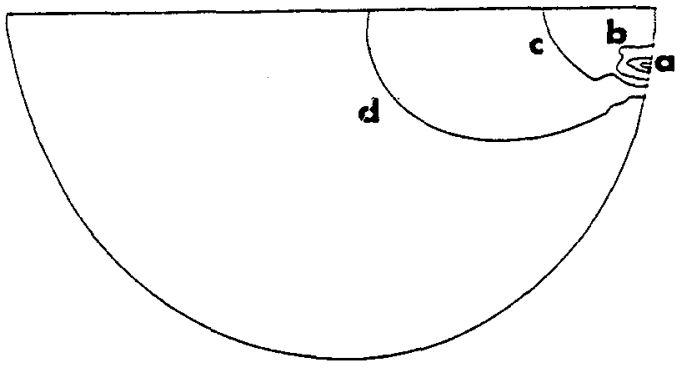

DYNAMIC $(2 \mu s)$

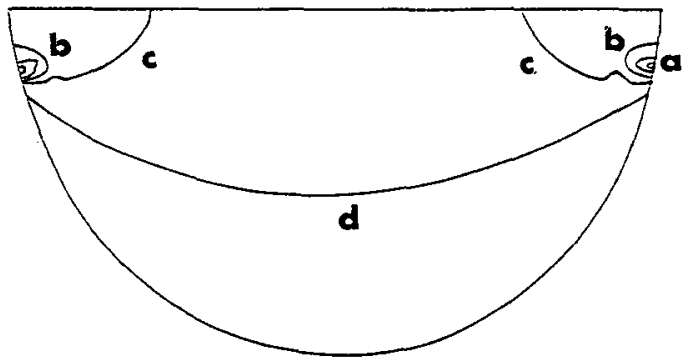

DYNAMIC $(8 \mu s)$

Figure 6. Dynamic stress contours. 


\section{DISCUSSION AND CONCLUSIONS.}

In this work, an experimental and numerical analysis has been carried out to study the possibilities of splitting tests in dynamic conditions. Regarding the three critical aspects previously mentioned in the introduction, we can conclude:

- Ceramic behaviour is well represented by a linear elastic model up to failure.

- It has been demonstrated, for the particular case analyzed (silicon carbide-silicon nitride compound), that the quasi-static equilibrium condition is reached before material fails. This statement can be generalized to other materials if a linear elastic behaviour is assumed for them, because the equilibrium will be ensured after several reverberations of elastic waves, which velocity is a material property. Thus, the only thing to take into account is the specimen size.

- The failure pattern must guarantee the validity of the expression traditionally used, that is, the rupture must be localized in the diameter coincident with the application of the load. In the tests carried out, different cases had been found. Although most of them could be classified as "valid tests", there had been others in which failure was not adequate. For this reason, the assistance of the high speed photography technique was essential to distinguish between "valid" and "invalid" tests.

In summary, the analysis developed indicates that splitting tests can be an alternative way to determine the dynamic tensile strength of brittle materials. However, another aspects should be taken into account in future researches: 1) The high speed images show a small broken area near the point of load application. If this observation is confirmed in other materials, special supports should be designed to avoid any stress concentration in these zones. Probably, this is the reason of the lower values obtained in dynamic conditions for the alumina specimens, as indicated in table $1 ; 2$ ) In this type of tests the material is subjected to a biaxial stress state (tension and compression). It should be important to evaluate the influence of the compression stress in the tensile strength values.

\section{Acknowledgements.}

The authors are indebted to the Comisión Interministerial de Ciencia y Tecnología for the financial support of this work through project MAT92-0086. Thanks are also extended to Laboratorio Químico Central de Armamento for the facilities provided to carry out the experimental programme.

\section{REFERENCES.}

[1] A.M.Neville. "Properties of Concrete", (1973) Pitman Publishing.

[2] ASTM C 496-71, " Splitting Tensile Strength of Cylindrical Concrete Specimens “.

[3] USERS ABAQUS MANUAL (1989), Hibbitt, Karlsonn \& Sorensen Company.

[4] S. Timoshenko and J.N. Goodier. "Teoría de la Elasticidad", (1975) Editorial Urmo, Bilbao.

[5] P.S. Follansbee. “ High Strain Rate Compression Testing “, Handbook of Metals (1985), 8th Edn.Vol.8, 190.

[6] H.F. Swift . "Image Forming Instruments", In "Impact Dynamics", (1982), (J.A.Zukas, T.Nicholas, H.F.Swift, L.B. Greszczuk y D.R. Curran, Eds.) . John Wiley \& Sons, New York 